\title{
The Cost Incurred for the Treatment among the Cancer Patients in Coimbatore
}

\section{OPEN ACCESS}

Manuscript ID:

ECO-2021-09044218

Volume: 9

Issue: 4

Month: September

Year: 2021

P-ISSN: 2319-961X

E-ISSN: 2582-0192

Received: 15.06.2021

Accepted: 09.08.2021

Published: 01.09.2021

Citation:

Sangamithra, A., and S. Vishnu. "The Cost Incurred for the Treatment among the Cancer Patients in Coimbatore." Shanlax International Journal of Economics, vol. 9, no. 4, 2021, pp. 49-53.

DOI:

https://doi.org/10.34293/ economics.v9i4.4218

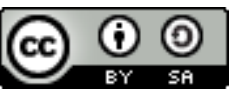

This work is licensed under a Creative Commons Attribution-ShareAlike 4.0 International License

\author{
A. Sangamithra \\ Professor, Department of Economics \\ Bharathiar University, Coimbatore, Tamil Nadu, India \\ Ditps://orcid.org/0000-0003-4761-8150
}

\section{S. Vishnu}

Ph.D. Research Scholar, Department of Economics

Bharathiar University, Coimbatore, Tamil Nadu, India

iD https://orcid.org/0000-0001-9182-4758

\begin{abstract}
According to the World Health Organization (WHO), each year universally, about 14 million people have realized that they have cancer and eight million individuals die from cancer. Cancer is a term for a group of diseases that can affect any part of the human body. Some more terms used are malignant tumors and neoplasms. Defining cancer is the quick creation of abnormal body cells that develop outside their usual borders and occupy adjoining parts of the body and extent to another organ of the body. The study aims to assess the cost incurred for Treatment among cancer patients in Coimbatore. The research source is from both primary and secondary data. The primary data was collected from two hospitals in Coimbatore through constructed exit interview schedule and secondary sources from from other various journals and articles.
\end{abstract}

Keywords: Health, Cancer, Cost, Direct cost, Indirect cost

\section{Introduction}

The World Health Organization (1948) has defined health as "A state of complete physical, mental and social wellbeing and not merely an absence of disease or infirmity." The difficulty in defining health is reflected in the relationship between health care and health status. Thus the maintenance of health may be seen to involve, for many, not just the treatment of disease but also the prevention of disease. On any other level, it may additionally be argued that the protection of health is additionally linked to the social environment. In this respect, health may be linked to, for example, unemployment and wealth. The domain of the term 'Health' is as large and complex as the entire scope of human activities. Good health is a prerequisite to human productiveness and the improvement process. A healthy community constitutes the infrastructure needed for building an economically viable society. Health is vital for the ethical, artistic, material, and spiritual development of man. Health is not just feeling good but is concerned with social, emotional, physical, and mental aspects. It consists of the cognitive, affective, and motion domains of human conduct as it refers no longer solely to men and women however additionally to the skills of families, communities, institutions, and societies (Ramanujam, 2009).

\section{Objective}

- To find out the cost incurred for the Treatment among sample respondents of the cancer patients in Coimbatore. 


\section{Data Sources and Methodology}

Although a study has been conducted to assess the cancer patients and its risks factor burden in many regions of India, understanding this problem, the researcher planned to conduct her survey in Coimbatore city. The city has a large number of hospitals both in the public and private sectors. Apart from government hospitals, several multifacility hospitals function in the city. The remarkable treatment with advanced science and technology with better patient care in the city hospitals can be attributed to the right perspective vision of the industrialists turned philanthropists here who bridged the gap between the growing health needs and the existing services to serve the society. The Data was collected from two hospitals through constructed interview schedule in January 2021. Analysis was done, making use of the frequency tables.

\section{Reviews of Literature}

G. K. Rath, et al., (1995) studied the cost of managing tobacco-related cancers in India. It has been hypothesized by using many scientists that the expenditure incurred on the remedy of tobaccorelated illnesses is a top deal greater than the earnings generated by using tobacco. The Indian Council of Medical Research initiated a task to check this hypothesis. This file affords the preliminary effects of the value of administration of tobacco-related cancers. A complete of 342 sufferers had been interviewed concerning the expenditure incurred via them or their relatives/friends earlier than achieving the hospital, on analysis and cure of the disease, including charges incurred on travel, lodging, and food. Dikshit R et al., (2012) argued that the agespecific mortality rates and total deaths from specific cancers had not been documented for the various regions and subpopulations of India. And so this learns about assessing the impact of the loss of life in 2001-03 in houses in small areas that had been chosen to be consultant of all the components of the state. Mohammad Akhtar Hussain et al., (2012) argues that the burden of cancer is growing globally and is one of the top leading causes of death. Also, the study thinks that the information on cancer patterns is essential for effective planning of cancer control interventions. There are limited published articles available on the outline of cancer for the state of Odissa, India. The present study was an attempt to explore the design and trend of cancer in Odissa. To fulfill the objectives, retrospective data from 2001-2011 at Acharya Harihar Regional Cancer Center (ACC), Cuttack, Odisha, were analyzed. Medical files of most cancers sufferers had been reviewed and applicable facts on diagnosis, major site, and demographic records have been retrieved. Ajay Mahal et al., (2013) assessed the burden of most cancers on households' out-of-pocket health spending, non-medical consumption, group of people participation, and debt and asset profits the utilization of information from a nationally guide health and morbidity survey in India for 2004 of nearly seventy four thousand households. Propensity rankings have been used to fit households containing a member recognized with most cancers to households with comparable socioeconomic and demographic characteristics. The estimates are primarily based on records from 1,645 households chosen via matching. Cancer-affected households skilled greater ranges of outpatient visits and health facility admissions and expanded out-of-pocket health fees per member relative to controls. Cancer-affected households spent between Indian Rupees sixtysix and eighty five greater per member on healthcare over a 15day reference period than controls and extra charges (per person) received on inpatient care with the aid of cancer-affected households yearly is equal to 36 percentage to forty four percentage of annual family costs of matched controls. Members without cancer in cancer-affected households used less health care and spent less on healthcare.

\section{Cost Incurred for the Treatment}

The cost of the disease is hooked on many variables. These encompass the kind of disease, the number and severity of issues and the demographic traits of the learn about population. In a diverse society like India, with the unlimited disparity in earning, access to medical care, and differing superiority of care, all factors must be taken into account to get the correct picture. The lack of medical histories makes it even more difficult to conduct such research (Kapur, A.2001). Direct economic costs of the disease are those made by the resources 
used in treating or coping with a disease, including expenditure for medical care and the treatment of the disease, hospital care, physician services, nursing home care, drugs, and other medical needs. These direct costs are frequently easily measured by surveys and studies. Recently, researchers have also advocated the inclusion of direct non-medical costs, including the transportation costs of patients and the costs of caregiving by family members.

\section{Direct Cost of the Respondents}

The table below depicts the burden of cancer, showing the total of both direct and indirect costs. The table below shows the total of both direct and indirect costs of the patients viz. Admission fee, Doctor fee, Medicine, diagnostic surgery, ICU, and room rental come under the direct cost. Direct costs components incurred repeatedly during The treatment process. Transport charges and food expenses will come under the indirect cost. The details are given below.

Table 1 Direct cost (In Rs)

\begin{tabular}{|l|c|c|c|c|c|}
\hline \multicolumn{3}{|c|}{ Per Month (In Rs) } & \multicolumn{3}{c|}{ Per Year (In Rs) } \\
\hline Direct Expense & Frequency & Percent & Direct Expense & Frequency & Percent \\
\hline $\mathbf{5 0 0 - 2 4 9 9}$ & 5 & 20.0 & Below-19999 & 3 & 12.0 \\
\hline $\mathbf{2 5 0 0 - 4 4 9 9}$ & 5 & 20.0 & $20000-39999$ & 9 & 36.0 \\
\hline $\mathbf{4 5 0 0 - 6 4 9 9}$ & 3 & 12.0 & $40000-59999$ & 8 & 32.0 \\
\hline $\mathbf{6 5 0 0 - 8 4 9 9}$ & 10 & 40.0 & $60000-79999$ & 3 & 12.0 \\
\hline $\mathbf{8 5 0 0 - A b o v e}$ & 2 & 8.0 & $80000-$ above & 2 & 8.0 \\
\hline Total & $\mathbf{2 5}$ & $\mathbf{1 0 0}$ & Total & $\mathbf{2 5}$ & $\mathbf{1 0 0}$ \\
\hline
\end{tabular}

Source: Primary Data

Table 1 explains the direct costs of the samples, 5 respondents (i.e. 20 percent) have used between Rs.500toRs.2499 per month, 3 respondents (i.e.12percent) have used below Rs.19999 per year,5 respondents (i.e.20percent) have used between 2500 to Rs.4499 per month, 9 respondents (i.e.36 percent) have used between Rs.20000 to Rs.39999 per year, followed by 3 respondents(i.e. 12 percent) have used between Rs.4500 to Rs.6499 per month, 8 respondents (i.e. 32 percent) have used from Rs.40000 to Rs.59999 per year, 10 respondents (i.e. 40 percent) have used from Rs.6500 to Rs.8499per month, correspondingly 3 respondent (i.e. 12 percent) have used from Rs.60000 to Rs.79999 per year, similarly, 2 respondent (i.e. 8 percent) have used Rs. 8500 and above per month, in the same way, 2 respondents (i.e. 8 percent) have used Rs. 80000 and above per year.

\section{Indirect Cost of the Respondents}

Components of the household health costs incurred and disease management the total of direct nonmedical expenditure include the expenditure incurred on transportation and food expenditure. The details are presented below in the table.

Table 2 Indirect costs (In Rs)

\begin{tabular}{|l|c|c|c|c|c|}
\hline \multicolumn{3}{|c|}{ Per Month (In Rs) } & \multicolumn{3}{c|}{ Per Year (In Rs) } \\
\hline Indirect Expenditure & Frequency & Percent & Indirect Expenditure & Frequency & Percent \\
\hline $\mathbf{1 0 0 - 2 9 9}$ & 6 & 24.0 & Below-3000 & 5 & 20.0 \\
\hline $\mathbf{3 0 0 - 4 9 9}$ & 11 & 44.0 & $3001-5000$ & 16 & 64.0 \\
\hline $\mathbf{5 0 0 - 6 9 9}$ & 8 & 24.0 & 5001 -above & 4 & 16.0 \\
\hline Total & 25 & 100 & Total & 25 & 100 \\
\hline
\end{tabular}

Source: Primary Data

Table-2 shows the indirect expenditure of the respondents; the indirect costs are based on per month and year, 6 respondents (i.e. 24 percent) have to spend between Rs.100 to Rs.299 as per month.5 
respondents (i.e. 20 percent) have to spend below Rs.3000 per year,11 respondents (i.e. 44 percent) have to spend between Rs.300 to Rs.499, and 16 respondents (i.e.64 percent) have to spend from Rs.3001 to Rs.5000 per year, correspondingly 8 respondents(i.e.24 percent) have to spend fromRs.500toRs.699 per month, and 4 respondents (i.e.16 percent) have to spend from Rs.5001 and above respectively.

\section{Conclusion}

A plan for the diagnosis and treatment of cancer is a key factor of any entire cancer control plan. Is the main aim is to cure cancer patients or prolong their life considerably, ensuring a good quality of life. For a diagnosis and treatment program to be effective, it must never be developed in isolation. It needs to be linked to an early detection program so that cases are noticed early when treatment is more effective and there is a greater chance of cure. It also needs to be integrated with a palliative care program so that patients with progressive cancers, who can no longer benefit from treatment, will get adequate relief from their physical, psychosocial, and spiritual suffering.

Furthermore, programs should include an awareness-raising component to educate patients, families, and community members about the cancer risk factors and the need for taking preventive measures to avoid developing cancer. The latest advances in cancer treatment have created a whole new viewpoint on how to treat cancer. These advances have developed from a deeper perception of the molecular groundwork of cancer. Some of the before redress is nevertheless treasured. Then again, they have some drawbacks. For example, surgical treatment and radiation are high-quality; however, they solely deal with one neighborhood place of cancer. Chemotherapy can deal with most cancer cells unfolding all over the physique however they have extraordinarily poisonous aspect effects. All of these redresses are nevertheless in use nowadays and will possibly be in use for a whilst though they will now not be the solely form of treatment.

\section{Acknowledgment}

The study is a part of the RUSA 2.0 Bharathiar Cancer Theranostics Research Centre (BCTRC) funded Project from 2021 to 2022. The project entitled Economic Consequence of Coping of Mechanism of Cancer Patients.

\section{References}

Aizer, Ayal A., et al. "Lack of Reduction in Racial Disparities in Cancer - Specific Mortality over a 20-year Period." Cancer, 2014.

Aziz, Noreen M., and Julia H. Rowland. "Trends and Advances in Cancer Survivor Research: Challenge and Opportunity." Seminars in Radiation Oncology, vol. 13, no. 3, 2003, pp. 248-266.

Beckjord, Ellen Burke, et al. "Health-related Information Needs in a Large and Diverse Sample of Adult Cancer Survivors: Implications for Cancer Care." Journal of Cancer Survivorship, vol. 2, 2008, pp. 179189.

Blanch-Hartigan, Danielle, et al. "Provision and Discussion of Survivorship Health Care Plans among Cancer Survivors: Results of a Nationally Representative Survey of Oncologists and Primary Care Physicians." Journal of Clinical Oncology, vol. 32, 2014.

Brearley, S.G., et al. "The Physical and Practical Problems Experienced by Cancer Survivors." European Journal of Oncology Nursing, vol. 15, no. 3, 2011, pp. 204-212.

Earle, Craig C. "Failing to Plan is Planning to Fail: Improving the Quality of Care with Survivorship Health Care Plans." Journal of Clinical Oncology, vol. 24, 2006.

Erikson, Clese, et al. "Future Supply and Demand for Oncologists: Challenges to Assuring Access to Oncology Services." Journal of Oncology Practice, vol. 3, 2007, pp. 79-86.

Gilbert, Scott M., et al. "Cancer Survivorship: Challenges and Changing Paradigms." The Journal of Urology, 2008.

Hewitt, Maria, et al. Childhood Cancer Survivorship: Improving Care and Quality of Life. National Academies Press, 2003.

Hordern, Amanda, and Annette Street. "Issues of Intimacy and Sex in the Face of Cancer: The Patient Caring Perspective." Cancer Nursing, vol. 30, 2007. 
Joanna, Pryce, et al. "Cancer Survivorship and Work: Symptoms, Supervisor Response, Co-Worker Disclosure and Work Adjustment." Journal of Occupational Rehabilitation, vol. 17, 2007, pp. 83-92.

Kim, Youngmee, and Barbara A Given. "Quality of Life of Family Caregivers of Cancer Survivors: Across the Trajectory of the Illness." Cancer, 2008.

Kim, Youngmee, et al. "Needs Assessment of Family Caregivers of Cancer Survivors: Three Cohorts Comparison." Psycho-Oncology, vol. 19, 2010, pp. 573-582.

Levit Laura, et al. Delivering High-Quality Cancer Care: Charting New Course for a System in Crisis. National Academies Press, 2013.

Mariotto, Angela B., et al. "Projections of the Cost of Cancer Care in the United States." Journal of the National Cancer Institute, vol. 103, 2011, pp. 117-128.

Miller, Kenneth D., and Laura R. Triano. "Medical Issues in Cancer Survivors - A Review." The Cancer Journal, vol. 14, no. 6, 2008, pp. 375387.

Oeffinger, Kevin C., and Mary S. McCabe. "Models for Delivering Survivorship Care." Journal of Clinical Oncology, vol. 24, 2006.

Oeffinger, Kevin C., et al. "Chronic Health
Conditions in Adult Survivors of Childhood Cancer." New England Journal of Medicine, 2006.

Paskett, Electra D., et al. "Patient Navigation: An Update on the State of the Science." CA: A Cancer Journal for Clinicians, vol. 61, 2011, pp. 237-249.

Patnaik, Jennifer L., et al. "Cardiovascular Disease Competes with Breast Cancer as the Leading Cause of Death for Older Females diagnosed with Breast Cancer: A Retrospective Cohort Study." Breast Cancer, vol. 13, 2011.

Salz, Talya, et al. "Survivorship Care Plans in Research and Practice." CA: A Cancer Journal for Clinicians, vol. 62, no. 2, 2012, pp. 101-117.

Siegel, Rebecca, et al. "Cancer Treatment and Survivorship Statistics, 2012.” CA: A Cancer Journal for Clinicians, vol. 62, no. 4, 2012, pp. 220-241.

Stanton, Annette L. "Psychosocial Concerns and Interventions for Cancer Survivors." Journal of Clinical Oncology, vol. 24, 2006.

Zeltzer, Lonnie K., et al. "Psychological Status in Childhood Cancer Survivors: A Report from the Childhood Cancer Survivor Study." Journal of Clinical Oncology, vol. 27, 2009.

\section{Author Details}

Dr. A. Sangamithra, Professor, Department of Economics, Bharathiar University, Coimbatore, Tamil Nadu, India

S. Vishnu, Ph.D. Research Scholar, Department of Economics, Bharathiar University, Coimbatore, Tamil Nadu, India, Email ID: vssss572@gmail.com. 